\title{
Idiopathic acute eosinophilic pneumonia
}

INSERM

\section{Source}

INSERM. (1999). Orphanet: an online rare disease and orphan drug data base. Idiopathic acute eosinophilic pneumonia. ORPHA:724

Idiopathic acute eosinophilic pneumonia (IAEP) is an eosinophilic pneumonia of undetermined etiology that is characterized by acute febrile hypoxic respiratory failure associated with diffuse radiog raphic infiltrates and pulmonary eosinophilia, but without concurring allergy or infection. 